\title{
Refractive development in children with Down's syndrome: a population based, longitudinal study
}

\author{
Olav H Haugen, Gunnar Høvding, Isa Lundström
}

\begin{abstract}
Aims-To study the refractive development in children with Down's syndrome longitudinally.

Methods-An unselected population of 60 children with Down's syndrome was followed with repeated retinoscopies in cycloplegia for 2 years or more (follow up 55 (SD 23) months). Accommodation was assessed with dynamic retinoscopy.

Results-From longitudinal spherical equivalent values of the right eye, three main categories of refraction were defined: stable hypermetropia $(<1.5 \mathrm{D}$ difference between the first and last visit) $(n=34)$, increasing hypermetropia ("hypermetropic shift"; $\geqslant 1.5 \mathrm{D}$ difference) $(n=11)$, and decreasing hypermetropial development of myopia ("myopic shift"; $\geqslant 1.5 \mathrm{D}$ difference) $(\mathrm{n}=9)$. Patients with anisometropia $(n=6)$ were evaluated separately. In the stable hypermetropia group three sublevels were chosen: low $(\leqslant+2.0 \mathrm{D}$ at the last visit), moderate $(+2.25$ to +4.0 $\mathrm{D})$, and high $(>+4.0 \mathrm{D})$. An accommodation weakness was found in $55 \%$ of the children. Accommodation weakness was significantly less frequent in the stable, low grade hypermetropia group (22\%) than in all the other groups $(p=0.008)$. The frequency of astigmatism $\geqslant 1.0 \mathrm{D}$ at the last visit was $57 \%$, the direction of axis being predominantly "with the rule." All the eyes with oblique astigmatism had a side specific direction of axis; the right eyes belonging to the $135^{\circ}$ axis group and the left eyes to the $45^{\circ}$ axis group.

Conclusion-A stable, low grade hypermetropia was significantly correlated with a normal accommodation. Accommodation weakness may be of aetiological importance to the high frequency of refractive errors encountered in patients with Down's syndrome. A striking rightleft specificity in the oblique astigmatic eyes suggests that mechanical factors on the cornea from the upward slanting palpebral fissures may be a major aetiological factor in the astigmatism. (Br f Ophthalmol 2001;85:714-719)
\end{abstract}

The increased frequency of refractive errors in individuals with Down's syndrome has been documented by many authors. ${ }^{1-9}$ However, most studies have been based on selected populations. ${ }^{1-6}$ In addition, all reports so far have been cross sectional studies.
Hoping to elucidate new aspects of this issue, we have studied the refractive development in an unselected Down's syndrome childhood population by repeated examinations during the past 10 years. To our knowledge, this is the first longitudinal study on refractive errors in children with Down's syndrome.

\section{Subjects and methods}

STUDY POPULATION

Seventy seven children with Down's syndrome born during the years 1988-99 in Hordaland County, Norway (population 416 000, annual births 6000), were referred from Vestlund Habilitation Resource Center to our department for an ophthalmological examination. This centre coordinates the habilitation of all Down's syndrome children in the county. To ensure a population based study design, the files of the regional laboratory for cytogenetics were examined. In this way we found 16 dropouts. Thus, the total number of patients with Down's syndrome born in our county during these years was 93, giving a mean annual incidence of 1.25 per 1000 live births (range 0.632.12).

Among the 16 dropouts, four had died and three had moved to other parts of the country. The other nine children were invited for an eye examination, which six of them attended. Valid data on previous refraction by other ophthalmologists could be obtained, and they were included in the study. Another six children moved to our region during the study period and were included in the study with successive examinations. Thus, 89 children with Down's syndrome born in the years 1988-99 were examined. Among these, 40 had their first examination during the first year of life (mean age at examination 7.1 (SD 3.0) months, range 3-12). Cross sectional data from these 40 infants will be presented separately.

Patients with follow up time $<2$ years $(n=29)$ were excluded from the longitudinal study. The group of children with Down's syndrome thus followed for $\geqslant 2$ years with repeated eye examinations consisted of 60 children (30 girls and 30 boys). Mean follow up time was 55 (SD 23) months (range 24-115). With very few exceptions, all the examinations were done by one of the authors $(\mathrm{OHH})$. In the whole longitudinal study group the mean age at the first examination was 21 (SD 14) months (range 3-61).

Informed consent was obtained from the parents, and the study was approved by the regional committee for medical research ethics. 
Table 1 Longitudinal refractive development in 60 children with Down's syndrome

\begin{tabular}{|c|c|c|}
\hline Group & Definition & $\begin{array}{l}\text { Number of } \\
\text { patients }\end{array}$ \\
\hline \multicolumn{3}{|l|}{ Isometropia } \\
\hline \multirow[t]{4}{*}{ Group 1} & Stable hypermetropia (spherical equivalent right eye $<1.5 \mathrm{D}$ difference between the first and last measurements) & 34 \\
\hline & (1a) low grade hypermetropia (spherical equivalent right eye $\leqslant+2.0$ at the last examination) & 18 \\
\hline & (1b) moderate hypermetropia (spherical equivalent right eye $+2.25-+4.0 \mathrm{D}$ at the last examination) & 12 \\
\hline & (1c) high grade hypermetropia (spherical equivalent right eye $>+4.0 \mathrm{D}$ at the last examination) & 4 \\
\hline Group 2 & Increasing hypermetropia (spherical equivalent right eye $\geqslant 1.5 \mathrm{D}$ difference between the first and last measurements) & 11 \\
\hline Group 3 & $\begin{array}{l}\text { Decreasing hypermetropia (spherical equivalent right eye } \geqslant 1.5 \mathrm{D} \text { difference between the first and last measurements) } \\
\text { or } \\
\text { development of myopia (spherical equivalent right eye }<0 \text { at the last examination) }\end{array}$ & 9 \\
\hline Anisometropia & Difference between right and left eye at the last examination $>1.0 \mathrm{D}$ spherical and/or $>1.5 \mathrm{D}$ cylinder power & 6 \\
\hline Total & & 60 \\
\hline
\end{tabular}

REFRACTIVE MEASUREMENTS

Retinoscopy in cycloplegia was performed using cyclopentolate $1 \%$ eye drops twice 30 minutes before the examination. Astigmatism was recorded as minus cylinders. The axis of astigmatism was classified as follows: 180 (SD $15)^{\circ}$ (" $180^{\circ}$ meridian" or "with the rule"), 90 (SD 15$)^{\circ}$ ("90 meridian" or "against the rule"), $16-74^{\circ}$ (" $45^{\circ}$ meridian"), and $106-$ $164^{\circ}$ (" $135^{\circ}$ meridian").

To evaluate the axis of oblique astigmatism in a mentally normal population, we used the
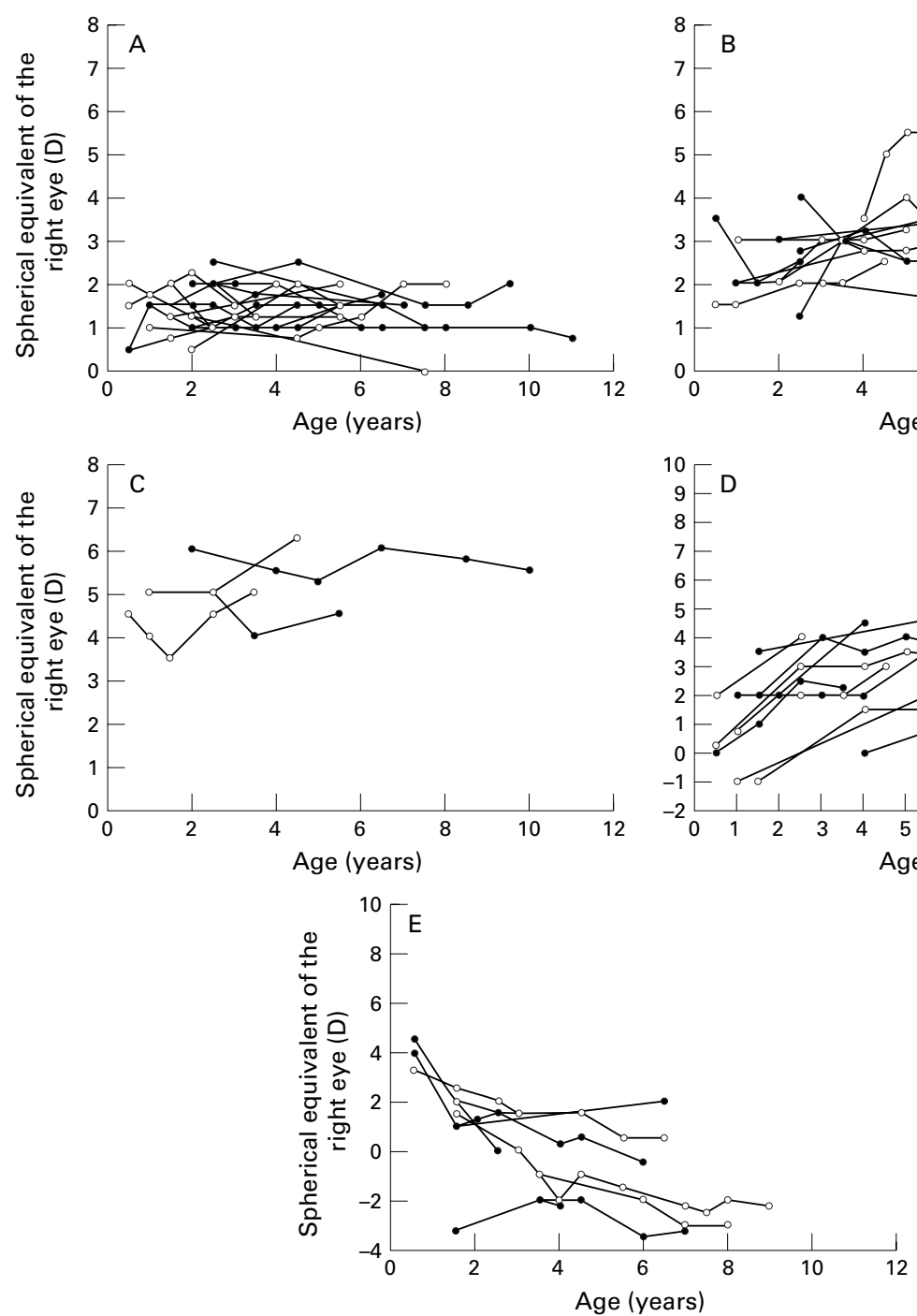

Figure 1 Individual curves of spherical equivalent values from children with Down's syndrome and stable, low grade hypermetropia (A), stable, moderate hypermetropia (B), stable, high grade hypermetropia (C), increasing hypermetropia (D), and decreasing hypermetropia or development of myopia (E).

preoperative refractive data from the excimer laser clinic in our department. Only patients referred for primary, uncomplicated refractive errors were included. Eyes with cylindrical power of $<1.0 \mathrm{D}$ were excluded. Thus, our control group included 365 eyes (172 right eyes, 193 left eyes) with astigmatism $\geqslant 1.0 \mathrm{D}$.

\section{ACCOMMODATION}

During the past 2-3 years of the study, each examination included an evaluation of the
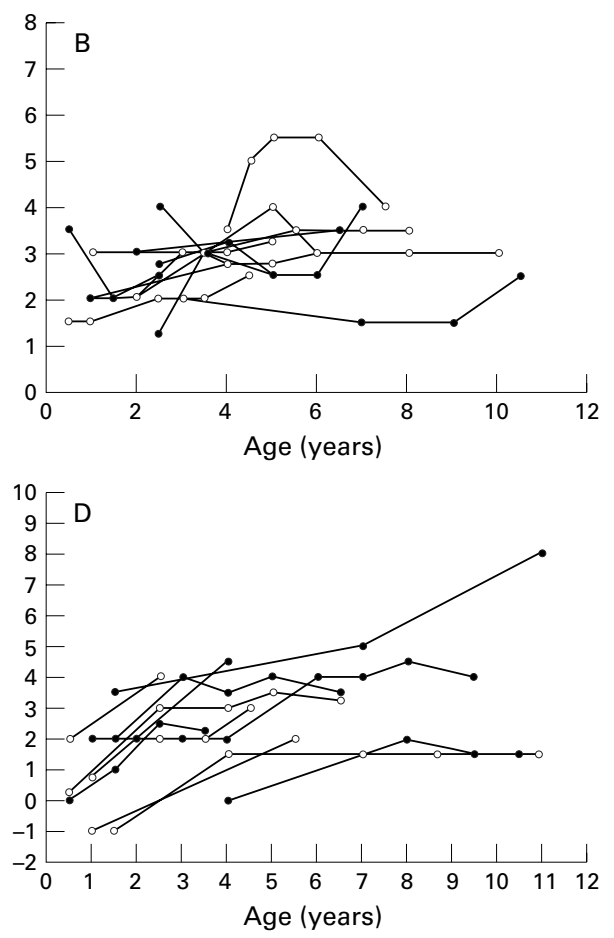
Table 2 Individual longitudinal data on 34 children with Down's syndrome with clinically significant astigmatism at the last examination (group C)

\begin{tabular}{|c|c|c|c|c|c|c|c|c|c|c|c|c|}
\hline \multirow{3}{*}{$\begin{array}{l}\text { Patient } \\
\text { no }\end{array}$} & \multirow{3}{*}{ Sex } & \multirow{3}{*}{$\begin{array}{l}\text { Age at first } \\
\text { examination } \\
\text { (months) }\end{array}$} & \multirow{3}{*}{$\begin{array}{l}\text { Age when } \\
\text { astigmatism was first } \\
\text { noted (months) }\end{array}$} & \multirow{3}{*}{$\begin{array}{l}\text { Age at last } \\
\text { examination } \\
\text { (months) }\end{array}$} & \multicolumn{4}{|l|}{ Right eye } & \multicolumn{4}{|l|}{ Left eye } \\
\hline & & & & & \multicolumn{2}{|l|}{ First visit } & \multicolumn{2}{|l|}{ Last visit } & \multicolumn{2}{|l|}{ First visit } & \multicolumn{2}{|l|}{ Last visit } \\
\hline & & & & & Cylinder (D) & Axis & Cylinder (D) & Axis & Cylinder (D) & Axis & Cylinder (D) & Axis \\
\hline 2 & $M$ & 25 & 25 & 70 & 2.0 & 180 & 2.0 & 175 & 2.0 & 180 & 2.0 & 5 \\
\hline 5 & $M$ & 47 & 90 & 132 & 0.5 & 180 & 0.5 & 135 & 2.5 & 10 & 2.5 & 10 \\
\hline 11 & $\mathrm{~F}$ & 33 & 33 & 59 & 1.5 & 180 & 2.0 & 165 & 1.5 & 180 & 2.0 & 15 \\
\hline 14 & M & 13 & 13 & 46 & 2.0 & 180 & 2.0 & 180 & 1.5 & 180 & 1.5 & 180 \\
\hline 16 & $M$ & 23 & 70 & 115 & 2.0 & 180 & 1.0 & 180 & 1.0 & 180 & 1.0 & 180 \\
\hline 22 & M & 22 & 22 & 66 & 1.0 & 180 & 1.0 & 180 & 1.0 & 180 & 1.0 & 180 \\
\hline 30 & $M$ & 11 & 11 & 48 & 1.5 & 180 & 1.0 & 175 & 1.5 & 180 & 1.0 & 180 \\
\hline 33 & M & 4 & 4 & 38 & 1.5 & 5 & 1.0 & 180 & 1.5 & 175 & 1.0 & 180 \\
\hline 35 & M & 20 & 20 & 66 & 2.5 & 180 & 3.0 & 175 & 2.5 & 180 & 4.5 & 180 \\
\hline 37 & $\mathrm{~F}$ & 45 & 70 & 82 & 1.0 & 180 & 1.5 & 180 & 1.5 & 180 & 1.5 & 180 \\
\hline 39 & M & 17 & 17 & 131 & 1.0 & 180 & 2.0 & 5 & 1.0 & 180 & 2.0 & 5 \\
\hline 46 & $\mathrm{~F}$ & 27 & 77 & 77 & 1.0 & 170 & 1.0 & 170 & 1.0 & 10 & 1.0 & 10 \\
\hline 47 & $\mathrm{~F}$ & 22 & 112 & 112 & 2.0 & 175 & 2.0 & 175 & 2.0 & 5 & 2.0 & 5 \\
\hline 48 & $\mathrm{~F}$ & 22 & 64 & 89 & 2.0 & 10 & 2.0 & 180 & 1.5 & 175 & 2.0 & 180 \\
\hline 58 & M & 7 & 7 & 33 & 3.0 & 180 & 2.0 & 180 & 3.0 & 180 & 1.5 & 10 \\
\hline 62 & M & 7 & 7 & 48 & 3.0 & 180 & 2.0 & 180 & 3.0 & 180 & 2.0 & 5 \\
\hline 64 & $\mathrm{~F}$ & 11 & 11 & 49 & 2.0 & 180 & 1.0 & 180 & 2.0 & 180 & 1.0 & 180 \\
\hline 65 & $\mathrm{~F}$ & 21 & 21 & 45 & 2.5 & 180 & 2.5 & 170 & 2.5 & 180 & 3.0 & 5 \\
\hline 81 & M & 17 & 17 & 72 & 2.0 & 180 & 3.0 & 170 & 2.0 & 180 & 3.0 & 5 \\
\hline 100 & M & 5 & 29 & 29 & 0 & - & 1.0 & 175 & 0 & - & 1.0 & 10 \\
\hline 19 & $\mathrm{~F}$ & 3 & 3 & 76 & 1.5 & 90 & 1.5 & 95 & 1.0 & 90 & 1.5 & 90 \\
\hline 38 & $\mathrm{~F}$ & 12 & 54 & 54 & 1.0 & 100 & 1.0 & 100 & 1.0 & 80 & 1.0 & 80 \\
\hline 54 & M & 25 & 45 & 87 & 0 & & 0 & - & 1.5 & 80 & 1.0 & 80 \\
\hline 3 & $\mathrm{~F}$ & 14 & 53 & 89 & 1.0 & 160 & 3.0 & 170 & 0 & - & 3.0 & 20 \\
\hline 6 & $\mathrm{~F}$ & 19 & 19 & 108 & 2.0 & 170 & 2.5 & 135 & 2.0 & 10 & 2.5 & 45 \\
\hline 13 & $\mathrm{~F}$ & 13 & 57 & 57 & 1.5 & 150 & 1.5 & 150 & 1.5 & 10 & 1.5 & 10 \\
\hline 29 & M & 20 & 20 & 77 & 1.0 & 180 & 1.0 & 170 & 1.0 & 180 & 1.5 & 20 \\
\hline 31 & M & 27 & 46 & 119 & 1.0 & 120 & 3.5 & 110 & 2.0 & 40 & 3.0 & 60 \\
\hline 36 & M & 53 & 53 & 106 & 1.5 & 125 & 2.0 & 140 & 1.5 & 35 & 1.5 & 50 \\
\hline 45 & $\mathrm{~F}$ & 23 & 53 & 112 & 2.0 & 120 & 2.5 & 120 & 2.5 & 40 & 2.5 & 45 \\
\hline 49 & $\mathrm{~F}$ & 33 & 33 & 84 & 1.5 & 135 & 0 & - & 2.0 & 60 & 1.0 & 80 \\
\hline 63 & M & 15 & 15 & 48 & 2.0 & 135 & 0 & - & 1.0 & 180 & 1.0 & 180 \\
\hline 76 & $\mathrm{~F}$ & 8 & 8 & 56 & 1.0 & 180 & 1.0 & 120 & 1.0 & 180 & 3.0 & 20 \\
\hline 88 & $\mathrm{~F}$ & 28 & 40 & 122 & 2.0 & 130 & 3.0 & 120 & 1.75 & 70 & 3.0 & 75 \\
\hline
\end{tabular}

accommodative function with dynamic retinoscopy. Several authors have found dynamic retinoscopy valuable in assessing the accommodative function, especially in children and in the mentally retarded. ${ }^{10-13}$ In most of these studies, the fixation target is mounted on the retinoscope, and the observer looks for the "breakdown" of the neutral retinoscopic reflex while constantly moving closer to the child. Because many of our Down's children became scared as the examiner moved close to them, the technique was modified as follows. In case of myopia, or hypermetropia $>+2.0 \mathrm{D}$, the child should wear his/her distant glass correction. Sitting about $50 \mathrm{~cm}$ in front of the child, the examiner observes the retinoscopic streak light movement while the child is looking straight ahead with both eyes open. A small picture that attracts interest (Lang's cube) is then introduced $20-30 \mathrm{~cm}$ in front of the child. The child is constantly encouraged to fixate the near target. If normal accommodation is present, the examiner observes a very distinct shift from "with" movements to "against" movements. Such a response was classified as "normal." If, when presenting the accommodative target, this clear shift did not take place in spite of a cooperative child, the accommodation response was classified as "accommodation weakness." The test was repeated three or more times.

VISUAL ACUITY

In infants and small children the visual acuity was tested with the Teller acuity card test. In older children we used an optotype test, mostly the Østerberg chart or the LH chart. In the most cooperative children, ordinary Snellen optotypes were used. Amblyopia was defined as a difference in visual acuity between the two eyes of more than one line on the acuity chart.

\section{STATISTICS}

The data were analysed statistically in the sPss 9.0 program, using the $\chi^{2}$ test and the Fisher's exact test. $\mathrm{p}=0.05$ was chosen as the level of significance.

\section{Results}

CROSS SECTIONAL DATA IN INFANTS

Twenty one $(53 \%)$ of the infants were emmetropic or hypermetropic $<+2.0 \mathrm{D}$, while 16 $(40 \%)$ were hypermetropic between +2.0 and $+5.25 \mathrm{D}$. There were three myopic children, all within $-1.5 \mathrm{D}$. Clinically significant astigmatism $(\geqslant 1.0 \mathrm{D})$ was present in 21 of 40 infants $(53 \%)$. In all but one case the astigmatism was bilateral. In one patient, the axis was "against the rule" bilaterally, in all the other cases (95\%) there was a "with the rule" astigmatism.

\section{LONGITUDINAL STUDY}

Six patients with clinically significant anisometropia at the last examination were regarded as one group. According to the development of the spherical equivalent of the right eye, the other 54 patients were classified into three main groups, presented in Table 1: group 1 stable hypermetropia (at different levels) $(\mathrm{n}=34)$; group 2 increasing hypermetropia $(\mathrm{n}=11)$, and group 3 decreasing hypermetropia or development of myopia $(n=9)$ (see Table 1 for the detailed definitions). The individual 


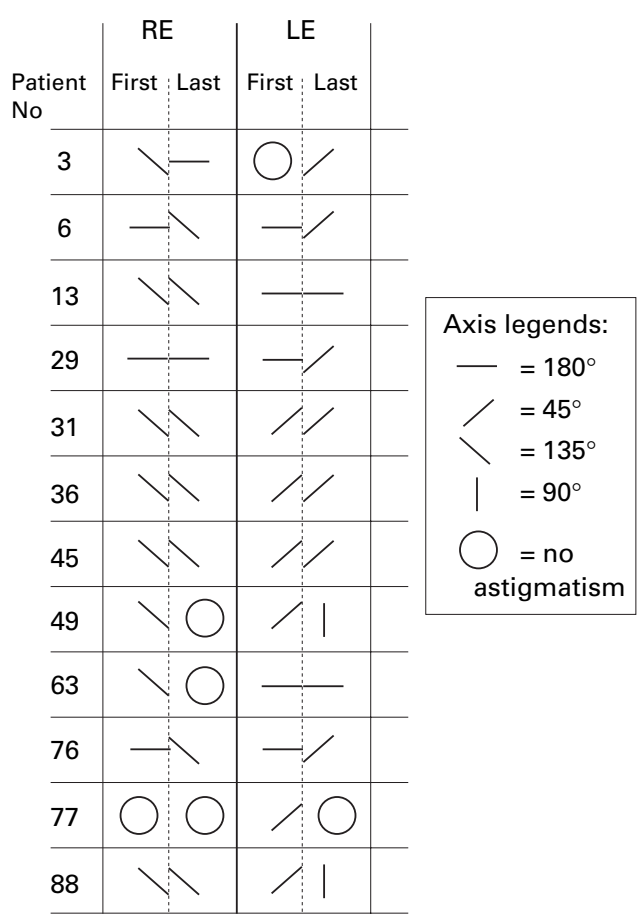

Figure 2 Direction of axis in the left and the right eyes in 12 children with Down's syndrome with oblique astigmatism. The signs in the columns "first" and "last" show the direction of the astigmatism when the astigmatism was first noticed and at the last examination, respectively (patient numbers correspond with Table 2).

longitudinal curves for each subgroup are shown in Figure 1A-E.

In group 2 ("hypermetropic shift") a level of stability (defined as three consecutive measurements differing $\leqslant 0.5 \mathrm{D}$ ) was reached in five patients $(45 \%)$, mean age at stability was 5.4 years (range 4-8 years). In group 3 ("myopic shift") only one patient demonstrated stability $(11 \%)$. This difference was not statistically significant.

\section{ASTIGMATISM}

Nineteen children (group A) had no clinically significant astigmatism during the study period. Seven children (group B) had a significant astigmatism at an early age, but it disappeared during the follow up period. The mean age at which the astigmatism disappeared in this group was 40 (SD 16) months (range 19-71). None of these patients had cylindrical values above $1.5 \mathrm{D}$.

Thirty four patients (57\%) had an astigmatism $\geqslant 1.0 \mathrm{D}$ in one or both eyes at the last visit (group C). In 19 patients the axis remained unchanged in the $180^{\circ}$ meridian throughout

Table 3 Accommodative ability in different refractive groups among 60 children with Down's syndrome

\begin{tabular}{|c|c|c|c|}
\hline \multirow[b]{2}{*}{ Refractive group } & \multicolumn{2}{|c|}{ Accommodation } & \multirow[b]{2}{*}{ Total } \\
\hline & Normal & Weak & \\
\hline \multicolumn{4}{|l|}{ Isometropia } \\
\hline Group 1a: stable, low grade hypermetropia & $14(78 \%)$ & $4(22 \%)$ & 18 \\
\hline Group 1b: stable, moderate hypermetropia & $6(50 \%)$ & $6(50 \%)$ & 12 \\
\hline Group 1c: stable, high grade hypermetropia & 0 & 4 & 4 \\
\hline Group 2: increasing hypermetropia & $4(36 \%)$ & $7(64 \%)$ & 11 \\
\hline Group 3: decreasing hypermetropia/development of myopia & $2(22 \%)$ & $7(78 \%)$ & 9 \\
\hline Anisometropia & $1(17 \%)$ & $5(83 \%)$ & 6 \\
\hline Total & $27(45 \%)$ & $33(55 \%)$ & $60(100 \%)$ \\
\hline
\end{tabular}

Table 4 Visual acuity in the better eye in 60 children with Down's syndrome

\begin{tabular}{llr}
\hline Test & Results & No of patients \\
\hline Teller acuity cards & $<4.8$ cycles/degree & 0 \\
$(\mathrm{n}=12)$ & 4.8 cycles/degree & 12 \\
& 9.8 cycles/degree & 0 \\
LH or Østerberg chart & $0.1-0.29$ & 6 \\
$(\mathrm{n}=35)$ & $0.3-0.49$ & 13 \\
& $0.5-0.69$ & 11 \\
Snellen chart & $0.7-1.0$ & 5 \\
$(\mathrm{n}=6)$ & $0.1-0.29$ & 0 \\
& $0.3-0.49$ & 2 \\
& $0.5-0.69$ & 4 \\
Not able to test & $0.7-1.0$ & 0 \\
Total & & 7 \\
& & 60 \\
\hline
\end{tabular}

the study period (upper part of Table 2). Three patients with "against the rule" astigmatism also had stable axes (middle part of Table 2). The lower part of Table 2 shows data from the 11 patients in group $\mathrm{C}$ with an oblique astigmatism at some point of the study period. All eyes that changed axis during the follow up period $(n=8)$ belonged to this subgroup (in bold). At the last examination, nine patients had an oblique astigmatism in one or both eyes. All the right eyes with oblique astigmatism had their axes in the $135^{\circ}$ meridian, while all the left eyes had their axes in the $45^{\circ}$ meridian. Figure 2 shows the axes of all the 12 patients with oblique astigmatism at any point of the study.

In the control group of patients referred to our excimer laser clinic, the right and left eyes with oblique astigmatism were equally distributed to the $45^{\circ}$ axis and the $135^{\circ}$ axis.

\section{ACCOMMODATION}

Accommodation weakness was found in 33 patients $(55 \%)$ (Table 3). However, the frequency was lower in the stable, low grade hypermetropic group than in the other groups $\left(\chi^{2}=14.7 ; \mathrm{df}=5 ; \mathrm{p}=0.008\right)$. Among those tested at two or more visits $(n=40)$, six changed from "normal" to "weak," while one child changed from "weak" to "normal."

\section{VISUAL ACUITY}

Visual acuity could be evaluated in 53 children $(88 \%)$ in the longitudinal study group (Table 4 ). In 27 children visual acuity could be recorded in each eye separately, while in 26 cases only binocular testing was possible. Only one of the children tested monocularly had a difference between the two eyes of more than one line on the acuity chart.

\section{Discussion}

DEVELOPMENT OF SPHERICAL EQUIVALENT

This study shows that about one third of the children with Down's syndrome (group 1a) had stable refractive values around emmetropia or low hypermetropia throughout preschool and early school age. Stable, but higher, values of hypermetropia were demonstrated in about one fourth of the children. Of special interest are the "hypermetropic shift" and "myopic shift" groups, leading to a persistent wide distribution of refractive values. In a normal refractive development, a low to medium grade hypermetropia with a wide 
Table 5 Astigmatism in infants: comparison between the present and previous studies

\begin{tabular}{|c|c|c|c|c|c|c|c|}
\hline \multirow[b]{2}{*}{ Author } & \multirow[b]{2}{*}{ Year } & \multirow[b]{2}{*}{ Method of refraction } & \multirow[b]{2}{*}{ No of patients (age) } & \multirow{2}{*}{$\begin{array}{l}\text { Astigmatism } \\
\geqslant 1.0 \mathrm{D}\end{array}$} & \multicolumn{3}{|l|}{ Axis } \\
\hline & & & & & WTR & $A T R$ & $O B L$ \\
\hline \multicolumn{8}{|l|}{ Normal infants } \\
\hline Mohindra $e t a l^{29}$ & 1978 & Non-cycloplegic & 276 (0-50 weeks) & $45 \%$ & \multicolumn{3}{|c|}{ Axis not reported } \\
\hline Ingram $e t a l^{30}$ & 1979 & Cycloplegic & 148 ( 1 year) & $30 \%$ & \multicolumn{3}{|c|}{ Axis not reported } \\
\hline Fulton $e t a l^{11}$ & 1980 & Cycloplegic & 75 (0-60 weeks) & $19 \%$ & $18 \%$ & $82 \%$ & $0 \%$ \\
\hline Gwiazda et $a l^{32}$ & 1984 & Non-cycloplegic & 521 (0-11 months) & $52 \%$ & $38 \%$ & $43 \%$ & $19 \%$ \\
\hline Dobson $e t a l^{33}$ & 1984 & Cycloplegic & 43 (0-18 months) & $20 \%$ & $20 \%$ & $76 \%$ & $4 \%$ \\
\hline Abrahamsson et al $\beta^{4}$ & 1988 & Cycloplegic & 299 (1 year) & $100 \% \star$ & $6 \%$ & $91 \%$ & $3 \%$ \\
\hline Ehrlich et $a l^{20}$ & 1997 & Cycloplegic & 254 (9 months) & $35 \%$ & $81 \%$ & $17 \%$ & $2 \%$ \\
\hline \multicolumn{8}{|c|}{ Down syndrome infants } \\
\hline Woodhouse et al ${ }^{9}$ & 1997 & Non-cycloplegic & 23 (3-12 months) & $26 \%$ & \multicolumn{3}{|c|}{ Axis not reported } \\
\hline Present study & 2001 & Cycloplegic & 40 (3-12 months) & $53 \%$ & $95 \%$ & $5 \%$ & $0 \%$ \\
\hline
\end{tabular}

*Astigmatism $\geqslant 1.0 \mathrm{D}$ was one of the inclusion criteria in this study.

WTR = "with the rule."

ATR = "against the rule."

$\mathrm{OBL}=$ oblique astigmatism.

distribution is present in infancy. ${ }^{14}{ }^{15}$ This corresponds well with our findings in the Down's syndrome infant group. During the second year of life, the mean refraction normally changes towards emmetropia or slight hypermetropia. At the same time the distribution of refractive values narrows (emmetropisation). ${ }^{16-20}$ Previous cross sectional studies ${ }^{921}$ indicate that this normal process does not occur in patients with Down's syndrome. Our longitudinal data support and further characterise this refractive distribution in children with Down's syndrome.

Inside the "hypermetropic shift" group, there were five patients ( $45 \%$ ) reaching a level of stability, while in the "myopic shift" group only one patient stabilised (11\%). Although this difference is not statistically significant, it may indicate that a refractive development in a myopic direction in individuals with Down's syndrome is more likely to continue into high and disabling values. This is also supported by clinical experience and reported by others. ${ }^{21}$

The present study confirms the high frequency $(55 \%)$ of accommodation weakness among children with Down's syndrome reported by others. ${ }^{1322} 23$ Interestingly, our data demonstrate that the stable, low grade hypermetropia group (corresponding to a normal refractive development) had a significantly lower frequency of accommodation weakness than the other refractive groups. This association between an accommodation weakness and a failing emmetropisation does not prove a causative relation. However, several animal studies have shown that optical defocus on the retina induces compensating eye growth. ${ }^{24-26} 27$ This supports the view that reduced accommodation in early age, causing a blurred retinal image for objects at near, may be of aetiological importance for the abnormal refractive development in children with Down's syndrome. Obviously, there must be additional factors, as a reduced accommodation would always shift the optical focus behind the retina and thus induce a myopic shift. This mechanism, therefore, does not explain the cases with increasing hypermetropia.

In addition to a high proportion of accommodation weakness in our material, six of the 40 patients who were repeatedly examined for accommodation showed a change from normal to defect accommodative function. This could indicate that an accommodative ability initially present might later be weakened or lost.

The underlying mechanisms accounting for the reduced accommodation remain unclear. Such factors may be central ${ }^{28}$ or peripheral in origin.

DEVELOPMENT OF ASTIGMATISM

The prevalence of astigmatism in our Down's syndrome infant group (53\%) was comparable with that of normal infants (Table 5). ${ }^{20}{ }^{29-34}$ However, it was considerably higher than that reported in Down's syndrome infants by Woodhouse et al. ${ }^{9}$ The present study strongly indicates that "with the rule" astigmatism is the predominant type of astigmatism in infants with Down's syndrome. This contrasts with the findings in normal infants, where "against the rule" astigmatism seems to be the most common type (Table 5).

At the last examination, $57 \%$ of the whole longitudinal study group had a clinically significant astigmatism. This equals the high frequency of astigmatism in infancy and contrasts with the normal development, in which a decline in astigmatism is seen during the second year of life. ${ }^{30}{ }^{35}$ Thus, the normal disappearance of astigmatism does not seem to take place in children with Down's syndrome.

Two thirds of the patients with clinically significant astigmatism at the last examination had stable axes during the whole follow up period. The 12 patients in whom an oblique astigmatism was recorded at least once in one or both eyes deserve particular attention. All the eight eyes changing axis belonged to this group. The axis of the oblique astigmatism in the right eyes was in all cases in the $135^{\circ}$ meridian, while all the oblique astigmatism in the left eyes was in the $45^{\circ}$ meridian. To our knowledge, this right-left specificity of oblique astigmatism in Down's syndrome has not previously been pointed out or commented on. The astigmatic axes are usually only reported as "with the rule," "against the rule," or oblique. We have only found one publication reporting the axes separately for the right and the left eyes in patients with Down's syndrome. ${ }^{1}$ In this report, 14 out of 15 eyes with oblique astigmatism showed the same right-left specific pattern as in our study. 
We have had the opportunity to review the refractive data on 50 teenagers (100 eyes) with Down's syndrome reported by Doyle et al. ${ }^{36}$ Fifty two eyes had cylindrical power $\geqslant 1.0 \mathrm{D}$. Among these, 21 had an oblique axis according to our definition. The direction of the axes showed the same right-left specificity as described above in 18 of these 21 eyes (86\%). These data on the right-left specific axes were not reported in the published article.

In normal adults, McKendrick and Brennan ${ }^{37}$ found that the right and the left eyes with oblique astigmatism were equally distributed to the $135^{\circ}$ and the $45^{\circ}$ meridian. This finding corresponds to the results of our preoperative measurements on the excimer laser patients.

We suggest that this right left specific direction of oblique astigmatism may be caused by the upward slanting of the palpebral fissure, first described in the original publication by Down. ${ }^{38}$ Not specifically for Down's syndrome, but as a general hypothesis, pressure from the eyelids has already been pointed out as a major aetiological factor of corneal astigmatism. ${ }^{32} 39$ Shapiro and France ${ }^{5}$ found that the angle of the palpebral fissure in Down's syndrome patients exceeded $10^{\circ}$ in $45 \%$ of the patients. In addition, Lowe ${ }^{1}$ reported a widening of the angle between the two anteroposterior orbital axes from the normal $45^{\circ}$ to $75^{\circ}$ in four skulls from Down's syndrome patients. Both these factors might contribute to the right-left specificity in oblique astigmatism in Down's syndrome.

In conclusion, our longitudinal study confirms an abnormal refractive development in children with Down's syndrome. A possible causative association to a poor accommodation needs to be further explored. A high frequency of accommodation weakness in children with Down's syndrome suggests a more liberal use of bifocal or progressive glasses than practised today. At present, however, it must be emphasised that although improving visual performances at near, it is uncertain whether the use of progressive or bifocal glasses will prevent an unfavourable refractive development in children with Down's syndrome.

We are grateful to Dr Stephen J Doyle and co-workers at Manchester Royal Eye Hospital, who put their data on teenagers with Down's syndrome at our disposal. The Medical Birth Registry of Norway (MBR) and the Laboratory for Cytogenetics, Center for Medical Genetics and Molecular Medicine, Haukeland University Hospital, Bergen, are gratefully acknowledged for their efforts to provide necessary information. We thank Birfor their efforts to provide necessary information. We thank Bitte Espehaug for valuable help with the statistical analyses.
gitt

1 Lowe RF. The eyes in mongolism. $\mathrm{Br} \mathcal{F}$ Ophthalmol 1949;33:131-74

2 Skeller E, Øster J. Eye symptoms in mongolism. Acta Ophthalmol (Copenh) 1951;24:149-61.

3 thatmol (Copenh) 1951;24:149-61. and in other mentally handicapped children. Br f Ophthaland in other mentally
mol 1967;51:469-74.

4 Jaeger EA. Ocular findings in Down's syndrome. Trans Am Ophthalmol Soc 1980;78:808-45.

5 Shapiro MB, France T. The ocular features of Down's syndrome. Am F Ophthalmol 1985;99:659-63

6 Hestnes A, Sand T, Fostad K. Ocular findings in Down's syndrome. $\mathcal{F}$ Ment Def Res 1991;35:194-203.
7 Roizen NJ, Mets MB, Blondis TA. Ophthalmic disorders in hildren with Down's syndrome. Dev Med Child Neurol 1994;36:594-600.

8 Berk AT, Saatci AO, Erçal MD, et al. Ocular findings in 55 patients with Down's syndrome. Ophthalmic Genet 1996; 17:15-9.

9 Woodhouse JM, Pakeman VH, Cregg M, et al. Refractive errors in young children with Down's syndrome. Optom Vis Sci 1997;74:844-51.

10 Guyton D, O'Connor GM. Dynamic retinoscopy. Curr Opin Ophthalmol 1991;2:78-80.

11 Schulz E. Estimation of accommodation in early childhood. Strabismus 1996;4:133-8.

12 Leat SJ, Gargon JL. Accommodative response in children and young adults using dynamic retinoscopy. Ophthal Physiol Opt 1996;16:375-84.

13 Woodhouse JM, Meades JS, Leat SJ, et al. Reduced accommodation in children with Down's syndrome. Invest Ophthalmol Vis Sci 1993;34:2382-7.

14 Cook RC, Glasscock RE. Refractive and ocular findings in the newborn. Am f Ophthalmol 1951;34:1407-13.

15 Goldschmidt E. Refraction in the newborn. Acta Ophthalmol (Copenh) 1969;47:570-8

16 Sorsby A, Benjamin B, Sheridan M. Refraction and its components during the growth of the eye from the age of 3 . Medical Research Councils Special Reports, Series No 301. London: HMSO, 1961:1-67.

17 Fabian G. Augenärztliche Reihenuntersuchung von 1200 Kindern im 2. Lebensjahr. Acta Ophthalmol (Copenh) 1966;44:473-9.

18 Mohindra I, Held R. Refraction in humans from birth to five years. In: Fledelius HC, Alsbirk PH, Goldschmidt E, eds. Doc Ophthalmol Proc, Series, vol 28. The Hague: Dr W Junk Publishers, 1981:19-27.

19 Gwiazda J, Thorn F, Bauer J, et al. Emmetropization and the progression of manifest refraction in children followed from infancy to puberty. Clin Vis Sci 1993;8:337-44.

20 Ehrlich DL, Braddick OJ, Atkinson J, et al. Infant emmetropization: Longitudinal changes in refraction components from nine to twenty months of age. Optom Vis Sci 1997;74:822-43.

21 Wesson MD, Maino DM. Oculovisual findings in children with Down's syndrome, cerebral palsy, and mental retardation without specific etiology. In: Maino DM, ed. Diagnosis and management of special populations. St Louis: Mosby, 1995:17-54

22 Lindstedt E. Failing accommodation in cases of Down's syndrome. Ophthalmic Genet 1983;3:191-2.

23 Woodhouse JM, Pakeman VH, Saunders KJ, et al. Visual acuity and accommodation in infants and young children acuity and accommodation in infants and young ch.

24 Schaeffel F, Glasser A, Howland HC. Accommodation, refractive error and eye growth in chickens. Vis Res 988;28:639-57.

25 Troilo D, Wallman J. The regulation of eye growth and refractive state: an experimental study of emmetropization. Vision Res 1991;31:1237-50.

26 Schaeffel F, Howland H. Properties of the feedback loops controlling eye growth and refractive state in chicken. Vision Res 1991;31:717-34.

27 Smith EL 3rd. Spectacle lenses and emmetropization: the role of optical defocus in regulating ocular development. Optom Vis Sci 1998;75:388-98.

28 Yates CM, Simpson J, Maloney AFJ, et al. Alzheimer-like cholinergic deficiency in Down's syndrome. Lancet 1980;2: 979.

29 Mohindra I, Held R, Gwiazda J, et al. Astigmatism in infants. Science 1978;202:329-30.

30 Ingram RM, Barr A. Changes in refraction between the ages of 1 and 31/2 years. Br f Ophthalmol 1979;63:339-42.

31 Fulton AB, Dobson V, Salem D, et al. Cycloplegic refraction in infants and young children. Am f Ophthalmol 1980;90: $239-47$

32 Gwiazda J, Scheiman M, Mohindra I, et al. Astigmatism in children: changes in axis and amount from birth to six years. Invest Ophthalmol Vis Sci 1984;25:88-92.

33 Dobson V, Fulton AB, Sebris SL. Cycloplegic refractions of infants and young children: the axis of astigmatism. Invest infants and young children: the axis

34 Abrahamsson M, Fabian G, Sjöstrand J. Changes in astigmatism between the ages of 1 and 4 years: a longitudinal study. Br F Ophthalmol 1988;72:145-9.

35 Atkinson J, Braddick O, French J. Infant astigmatism: its disappearance with age. Vision Res 1980;20:891-3.

36 Doyle SJ, Bullock J, Gray C, et al. Emmetropisation, axial length, and corneal topography in teenagers with Down's syndrome. Br 7 Ophthalmol 1998;82:793-6.

37 McKendrick AM, Brennan NA. The axis of astigmatism in right and left eye pairs. Optom Vis Sci 1997;74:668-75.

38 Down JLH. Observations on an ethnic classification of idiots. Clinical lectures and reports by the medical and surgical staff of the London hospital 1866;3:259-62.

39 Grosvenor T. What causes astigmatism? f Am Optom Assoc $1976 ; 47: 926-3$ 